\title{
REPRESENTAÇÕES SOCIAIS DA VELHICE E DO ENVELHECIMENTO NA ERA DIGITAL: REVISÃO DA LITERATURA
}

\author{
SOCIAL REPRESENTATIONS OF OLD AGE AND AGING IN THE DIGITAL TIMES: LITERATURE \\ REVIEW
}

REPRESENTACIONES SOCIALES DE LA VEJEZ Y EL ENVEJECIMIENTO EN LA ERA DIGITAL:
LITERATURA

\author{
Amanda Castro* \\ Brigido Vizeu Camargo*
}

\begin{abstract}
RESUMO
O presente artigo de revisão de literatura tem como objetivo analisar as representações sociais da velhice e do envelhecimento na era digital. A representatividade demográfica da população idosa traz um novo panorama ao processo de envelhecimento. A partir das atividades sociais e com o desenvolvimento de grupos voltados aos idosos e a construção social da "terceira idade", houve a propagação da ideia da "melhor idade" em oposição à velhice. As iniciativas e comunicações online, voltadas para a "melhor idade" tratam o envelhecimento como uma experiência gratificante, em que se é possível realizar os planos adiados ao longo da vida; portanto, ser feliz. Desse modo, a ênfase nos ganhos com a chegada da velhice com destaque para a "melhor idade" favorece a desconstrução da velhice associada a doenças, morte e inatividade, mas parece desconsiderar a pluralidade de experiências de envelhecimento.
\end{abstract}

Palavras-chave: Representações sociais. Envelhecimento. Internet. Velhice. Idoso.

\footnotetext{
Texto recebido em 26 de agosto de 2014 e aprovado para publicação em 15 de junho de 2015.

* Mestranda em Psicologia pelo Programa de Pós Graduação da Universidade Federal de Santa Catarina, área de concentração: Processos psicossociais, saúde e desenvolvimento psicológico, Linha de pesquisa: Cognição e representaçôes sociais. Psicóloga formada pela Universidade do Sul de Santa Catarina. Atualmente é bolsista de pós graduação da CAPES. Tem experiência na área de Psicologia, com ênfase em Psicologia Social. E-mail: amandacastrops@gmail.com

** Possui graduação em Psicologia pela Pontifícia Universidade Católica de Campinas (1977), Mestrado em Psicologia Social pela Pontifícia Universidade Católica de São Paulo (1985), DEA em Psicologia Social pela Université Paris 5/ École des Hautes Études en Sciences Sociales (1993), e Doutorado em Psicologia Social pela École des Hautes Études en Sciences Sociales (1997). Atualmente é professor associado da Universidade Federal de Santa Catarina, supervisor do Laboratório de Psicologia Social da Comunicação e da Cognição; diretor de pesquisa associado da Maison des Sciences de lHomme - Paris; professor visitante da Università Degli Studi di Padova - Itália; membro do Doutorado Europeu sobre Representaçôes Sociais e Comunicação - Universitá Degli Studi di Roma La Sapienza; membro do Centro de Investigação em Ciências e Tecnologias da Saúde da Universidade de Évora; conselheiro nato da Sociedade Brasileira de Psicologia; Ex-presidente da Federação Ibero-americana de Associações de Psicologia (FIAP); membro do conselho editorial dos periódicos: Psicologia. E-mail: brigido.camargo@yahoo. com.br
} 


\begin{abstract}
The present review of literature aims to analyze the social representations of old age and aging in the digital age. The demographic representativeness of the elderly population, brings a new perspective to the aging process. From the social activities and the development of groups geared to seniors and the social construction of "third age", was the spread of the idea of "best age" as opposed to old age. And online communications initiatives, aimed at "best age" treat aging as a rewarding experience, as it is possible to carry out the plans postponed throughout life and therefore be happy. Thus, the emphasis on gains from the onset of old age with emphasis on the "best age" favors deconstruction of old age associated diseases, death and inactivity, but seems to ignore the plurality of experiences of aging.
\end{abstract}

Keywords: Social representations. Aging . Internet. Old age. Elderly.

\title{
RESUMEN
}

La presente revisión de la literatura tiene como objetivo analizar las representaciones sociales de la vejez y el envejecimiento en la era digital. De las actividades sociales y el desarrollo de grupos dirigidos a la tercera edad y la construcción social de la "tercera edad", fue la difusión de la idea de la "mejor edad", en oposición a la vejez. Y las iniciativas de comunicación en línea, dirigidos a "mejor edad" envejecimiento tratar como una experiencia gratificante, ya que es posible llevar a cabo los planes pospuestos durante toda la vida y por lo tanto ser feliz. El énfasis en las ganancias derivadas de la aparición de la vejez, con énfasis en la "mejor edad" favorece la deconstrucción de las enfermedades asociadas con la edad antigua, la muerte y la inactividad, pero parece ignorar la pluralidad de experiencias de envejecimiento.

Palabras clave: Representaciones sociales. Envejecimiento. Internet. Viejo . Ancianos.

\section{INTRODUÇÃO}

0 envelhecimento populacional representa uma das aquisiçóes advindas dos avanços biotecnológicos do século XXI. De acordo com o Relatório sobre a Situação da População Mundial (UNFPA, 2011), dentre os sete bilhões de habitantes do mundo, 893 milhões são idosos. A "Síntese de Indicadores Sociais 2012”, divulgada pelo Instituto Brasileiro de Geografia e Estatística (IBGE, 2012) indica que - de 2001 a 2011 - o número de idosos com 60 anos ou mais passou de 15,5 milhões para 23,5 milhôes de pessoas. Devido a esse fenômeno demográfico, o envelhecimento tem sido um tema de interesse em pesquisas relacionadas à teoria das representações sociais. 
Moscovici (1985) afirma que as representações que fazemos a respeito do cotidiano têm por principal função tornar uma coisa desconhecida - ou não familiar - em algo familiar. Conforme definição de Jodelet (2001; p.22), a representação social, "[...] é uma forma de conhecimento, socialmente elaborada e partilhada, com um objetivo prático, e que contribui para a construção de uma realidade comum a um conjunto social".

O desenvolvimento de pesquisas que caracterizem os elementos das representaçôes sociais do envelhecimento é relevante, tendo em vista que "uma das variáveis importantes para o enfrentamento das perdas decorrentes do envelhecimento diz respeito às representações que as pessoas têm deste processo" (Magnabosco-Martins, Camargo, \& Biasus, 2009). As concepções acerca do envelhecimento atravessam os períodos históricos, tendo constantes adaptações e modificações na medida em que se ampliam os estudos sobreeste processo. No campo da Gerontologia e da Psicologia Social - especificamente tem-se observado, ao longo dos anos, o desenvolvimento de pesquisas e teorias contemplando a velhice. Com o advento da internet e a popularização do uso das redes sociais, surgem novas formas de transmitir informações sobre o envelhecimento e seus aspectos. Sob diversos enfoques que podem ser distintos ou complementares, as investigações sobre esse objeto contribuem para o entendimento dos diversos fatores relativos ao processo de envelhecimento e à velhice. Neste artigo, pretende-se destacar os estudos acerca das representações sociais da velhice e do envelhecimento desde o século XIX até a era digital, com a popularização da internet.

\section{VELHICE E ENVELHECIMENTO}

A partir da segunda metade do século XIX, o envelhecimento associado à velhice começou a ser tratado como uma etapa da vida, caracterizada pela decadência física e ausência de papéis sociais. Inicialmente, as pesquisas desenvolvidas focaram as modificações fisiológicas e perdas de sistemas vitais do organismo; posteriormente, nos primeiros 60 anos do século XX, a Psicologia adotou a perspectiva do envelhecimento como uma etapa de declínio. Nesse contexto, o declínio das funçôes cognitivas e os déficits observados com o avançar dos anos, seriam impeditivos para o idoso manter autonomia diante das demandas diárias (Neri, 2006).

Nova perspectiva, os estudos referentes ao envelhecimento são apresentados a partir da teoria do ciclo de vida de Erikson; posteriormente, discutida por Neri (2008). Essa teoria compreende o processo de desenvolvimento com base na vida humana em toda a sua extensão - da infância até a velhice - e considera as 
influências socioculturais na manifestação e resolução das crises durante o ciclo de vida. No entanto, as perdas relativas à independência física e autonomia não implicam necessariamente o declínio do funcionamento cognitivo e emocional; o idoso pode ativar mecanismos compensatórios para lidar com os limites físifcos que a idade lhe impóe. s (Neri, 2006).

As condições de vida, experiências individuais, o contexto social, histórico e cultural podem modificar o curso do desenvolvimento. Em virtude disso, as características socioculturais e psicossociais são relevantes para o modelo de envelhecimento bem sucedido como concebido por Baltes e Baltes (1990). Tais aspectos são abordados a partir das contribuições da Teoria do Desenvolvimento ao longo da vida (lifespan), em que o ciclo vital é concebido como uma contínua progressão do desenvolvimento, desde o nascimento até a morte, envolvendo perdas e ganhos ocasionados pelo envelhecimento e influenciadas pelo contexto em que se encontra o indivíduo. Nessa perspectiva, é possível compreender o envelhecimento bem sucedido a partir do equilíbrio entre perdas e ganhos, com a manutenção da atividade funcional da pessoa que envelhece, nos seus aspectos físicos, psicológicos e sociais (Baltes \& Baltes, 1990; Neri, 2006; Neri, 2013).

$\mathrm{Na}$ Segunda Assembleia Mundial sobre o Envelhecimento, realizada em 2002, foi apresentado um documento da Organização Mundial da Saúde (OMS) que instituiu três pilares para a política de envelhecimento ativo: participação, saúde e segurança. Nesse sentido, o envelhecimento ativo é associado à busca pela qualidade de vida, considerando saúde como um bem-estar físico, mental e social, conforme a definição da OMS (Fernández, 2002).

Considerando ainda a relação entre envelhecimento e atividade, gerontólogos alicerçados no construcionismo, passaram a reafirmar a necessidade da desconstrução radical das imagens negativas do envelhecimento. Conforme essa perspectiva é necessário elaborar um imaginário positivo, capaz de evocar imagens relativas à vitalidade e atividade, reconstruindo o curso do envelhecimento de forma positiva. Essa proposta, definida como envelhecimento positivo, considera que concepções e estereótipos que envolvem o envelhecimento e a velhice são construções sociais passíveis de modificação (Gergen \& Gergen, 2000).

Ao fazer menção ao processo do envelhecimento é importante salientar que este processo não pode ser considerado conceitualmente como sinônimo de velhice. A velhice é definida como etapa do desenvolvimento humano ao passo que o envelhecimento é o processo que - transversalmente - percorre essas etapas (Neri, 2006). O início da fase da velhice é instituído a partir dos 60 para países subdesenvolvidos e em desenvolvimento e 65 anos para países desenvolvidos. Para Neri (2006), a velhice corresponde à última fase do ciclo vital e é delimitada 
por eventos de natureza múltipla incluindo- por exemplo - perdas psicomotoras e afastamento social, já o envelhecimento seria o processo de mudanças pautado nas características biopsicossociais de cada indivíduo.

Magnabosco-Martins et al. (2009) investigaram as representaçôes sociais do idoso e da velhice em diferentes faixas etárias e salientam que a representação social da velhice tem sua objetificação na figura do idoso, com destaque para a polarização entre atividade e inatividade. Os participantes desta pesquisa tratam como equivalentes as palavras "velhice" (negativa) e "velho"; e as expressões "espírito jovem" (positiva) e "idoso jovem". Nesse contexto, o idoso considerado saudável seria aquele que permanece ativo, ao se atualizar diante de novas informações e se adaptar ao ritmo e desejos de seus familiares. Assim, a velhice parece estar associada ao envelhecimento com sucesso, em que há um equilíbrio entre ganhos e perdas, a partir da manutenção das atividades cotidianas.

O estudo das representaçóes sociais da velhice ou do processo de envelhecimento deve considerar também os estereótipos que permeiam o espaço social (Jodelet, 2009). Alguns objetos sociais podem ter conteúdos semelhantes ou idênticos compondo categorias de estereótipos e do núcleo das representações sociais. No estudo realizado por Moliner e Vidal (2003), os idosos são descritos pelos jovens como pessoas com muito tempo livre, que apresentam doenças, que possuem valores tradicionais, relacionados à experiência e sabedoria. Para os autores, os estereótipos acerca do idoso são similares às representaçôes sociais do idoso apresentadas pelos mesmos jovens. $\mathrm{O}$ envelhecimento como objeto social, mantém relações estruturais com amplas noções que podem representar objetos sociais relevantes para determinados grupos etários. Nesse sentido, parece crucial conceber o envelhecimento dentro de um sistema de representação, de um conjunto de representaçôes, que são interligadas e mutuamente dependentes entre si, formando uma estrutura de ordem mais elevada (Nagel, Contarello, \& Wachelke, 2011).

O processo de envelhecimento e a fase da velhice são objetos equivalentes no âmbito do pensamento social. O envelhecimento é compreendido socialmente como uma fase estanque da vida, sendo associado de um lado à figura do velho; de outro, ao termo mais positivo, vinculado à atividade: idoso. Acerca da representação social da velhice é possível indicar que há uma distinção entre o velho e o idoso, em que o velho é considerado aquele que se sente velho e o idoso é o que tem idade avançada, mas que não sente os sinais da velhice (MagnaboscoMartins et al., 2009; Veloz, Nascimento-Schulze, \& Camargo, 1999).

O estudo de Areosa (2006) demonstra certa influência sociocultural e de gênero nas representações sociais da velhice. Nesse estudo, as mulheres se consideram 
mais ativas e vaidosas que os homens: percebidos negativamente e apresentando pouco autocuidado e inatividade após a aposentadoria. Os participantes homens acreditam chegar à velhice antes das mulheres; por consequência, apresentam certa inatividade. Descrevem as mulheres após a chegada da velhice como mais ativas e engajadas em atividades sociais. Desse modo, a velhice não é uma etapa homogênea, mas permeada por várias influências, inclusive a de relações de gênero.

Como foi possível verificar, o envelhecimento populacional trouxe o interesse em caracterizar o pensamento leigo acerca deste processo em diversos setores da sociedade. Estes estudos buscaram caracterizar as "teorias de senso comum" elaboradas e partilhadas acerca do envelhecimento. Nos últimos anos, pesquisadores têm investigado os principais elementos das representaçôes sociais do envelhecimento, da velhice e do idoso.

\section{PRINCIPAIS ELEMENTOS DAS REPRESENTAÇÕES DO ENVELHECIMENTO: DADOS RELATADOS EM PESQUISAS}

O envelhecimento na condição de objeto social adquire crescente visibilidade e toma espaço no ambiente acadêmico, em decorrência do aumento significativo no número de idosos. Os estudos realizados por Veloz et al., (1999) ofereceram um caminho a seguir no estudo de representações sociais do envelhecimento. Esse estudo foi desenvolvido por meio de entrevistas com idosos e os resultados obtidos após análise de classificação hierárquica descendente apontam para três representaçôes sociais diferentes:

a) a primeira como representação doméstica e feminina relativa à perda dos laços familiares;

b) a segunda tipicamente masculina em que o envelhecimento é caracterizado como perda do ritmo de trabalho;

c) a terceira representação e a última mais utilitarista apresenta o envelhecimento como um desgaste natural (Veloz et al., 1999). Desse modo, tais representações parecem apontar influências socioculturais e de gênero na manifestação e resolução das crises durante o ciclo de vida, tal como descrito na Teoria do Ciclo de Vida (Neri, 2008).

Com relação às representações sociais da saúde na velhice, Teixeira, Nascimento-Schulze e Camargo (2002) realizaram pesquisas com grupos de idosos, trabalhadores da saúde e cuidadores de pessoas idosas. Em todos os grupos, 
a autonomia e independência foram associadas à ideia de idoso saudável. Para o grupo de cuidadores foram observadas representaçôes relacionadas ao estilo de vida, em que o envelhecimento saudável dependeria dos hábitos saudáveis do idoso, ao passo que - para os trabalhadores - a saúde na velhice estaria relacionada a fatores mentais. As representações sociais do envelhecimento vinculadas ao estilo de vida e condiçôes mentais parecem apresentar correspondência no conceito de envelhecimento ativo, proposto pela OMS e destacado por Fernández (2002), em que há maior ênfase na atividade, estilo de vida e na capacidade funcional daqueles que envelhecem, atribuindo aos indivíduos a responsabilidade por seu processo de envelhecer.

Ao investigarem as representações sociais da velhice entre idosos de instituição de longa permanência e de grupos de convivência, Araújo, Coutinho e Saldanha (2005) discutem a figura daqueles associada à saúde. Os idosos das instituições de longa permanência representaram a velhice como busca da saúde, associada ao binômio velhice-doença, marcada pelo "preconceito", em que a busca de "Deus" surge como estratégia de enfrentamento diante do surgimento de "doenças". Já as representaçôes compartilhadas pelos grupos de convivência de idosos apresentaram a velhice, na condição de Terceira Idade, como momento de fazer novos "amigos". Para ambos os grupos, os idosos são "abandonados" por seus familiares, sendo que de acordo com os idosos das instituiçôes de longa permanência isso provoca "tristeza", tendo em vista que a família é considerada "necessária" para o bem-estar na velhice.

De modo similar aos resultados obtidos entre os idosos das instituições de longa permanência, Fernandes de Araújo et al. (2005) apontam que os idosos - principalmente aqueles portadores de doenças crônicas - objetivam suas representações sociais da velhice com uma conotação negativa e comumente associada ao binômio: velhice-doença. Tendo em vista a diferença entre os elementos das representaçôes do idoso e da velhice, parece pertinente enfatizar a influência do contexto em que se encontram os indivíduos, as características individuais e grupais que influenciam o processo de envelhecimento e a formação das representações sociais.

Posteriormente, os estudos acerca das Representações sociais do envelhecimento tiveram sua expansão a partir de pesquisas sob o enfoque da abordagem estrutural. Para essa abordagem, toda representação social é dividida em elementos centrais e periféricos, onde os primeiros são mais resistentes à mudança. $\mathrm{O}$ núcleo central de uma representação social é formado pelos elementos mais consensuais que definem o objeto, sendo composto por elementos normativos e funcionais. Em torno do núcleo central, são organizados os elementos periféricos: os componentes mais acessíveis e mais concretos de uma representação. Esses 
apresentam um papel essencial na adaptação da representação às mudanças do contexto. A transformação de uma representação se opera a partir dos elementos periféricos, provocando mudanças e interpretações novas (Abric, 1998).

A partir da abordagem estrutural, Teixeira et al. (2007) analisaram o conteúdo das representações sociais do envelhecimento, utilizando a técnica de associação livre de palavras. Esse estudo destaca a relação entre perdas e ganhos associada às representações sociais do envelhecimento. No grupo das mulheres entre 25 e 35 anos e entre 40 e 50 anos as hipóteses de núcleos periféricos próximos e distantes apontaram para uma predominância dos aspectos negativos sobre os positivos, como: decadência, depressão, pobreza, doença, perda de autoestima. Já - no grupo acima de 60 anos - houve predomínio de aspectos positivos, tais como: sabedoria, maturidade, experiência, alegria, bonito, prazer, gostoso. Os diferentes grupos etários tiveram seu desenvolvimento permeado por distintos valores, vivenciando períodos históricos, econômicos e sociais diversos. Os dados destacados pelos autores indicam a ocorrência de variaçóes representacionais entre gerações. Conforme a Teoria do Desenvolvimento ao longo da vida, a idade, a história e as influências não normativas são fatores que interferem no processo de desenvolvimento humano, abrangendo - ao longo do envelhecimento aspectos de perdas e de ganhos (Neri, 2013). Tais dados justificam a importância do investimento em pesquisas intergeracionais, principalmente quando o objeto de estudo é a velhice ou o envelhecimento.

Wachelke et al. (2008) realizaram uma pesquisa com o objetivo de caracterizar os princípios organizadores da representação social de não-idosos acerca do envelhecimento. A partir de convites em uma rede social na internet, 469 indivíduos responderam um instrumento que solicitava a evocação de sete a dez palavras relativas ao envelhecimento. Após a realização de análises fatoriais de correspondência, os resultados encontrados destacam o envelhecimento na condição de perdas, como um período marcado por forte enfraquecimento e desgaste. $\mathrm{Na}$ condição de ganhos, caracterizado a partir de novas atividades, novos hábitos na rotina, acúmulo de sabedoria e aprendizado. Os participantes mais próximos da velhice enfatizam elementos ligados ao cotidiano, como a aposentadoria, convívio com a família, relevância de cuidar da saúde e novas ocupaçôes. Já os mais jovens, tratam o envelhecimento como uma realidade mais distante, levando a uma etapa inevitável com mudanças. Os dados obtidos enfatizam a relação entre perdas e ganhos e também reforçam a ideia da ocorrência de modificações nas representações do envelhecimento ao longo do processo de desenvolvimento do indivíduo (Wachelke et al., 2008).

O artigo de Pecora, Anjos e Paredes (2010) apresenta parte dos resultados de uma pesquisa acerca das representações sociais do envelhecer para professoras 
da rede municipal de ensino de Cuiabá. Para tanto, foi utilizado o termo indutor "envelhecer" a partir da técnica de evocação livre;; posteriormente, foi identificada a estrutura e o conteúdo das representações investigadas e realizada a análise de similitude. Os dados encontrados sugerem que as representaçôes sociais do envelhecer são organizadas e têm seu significado construído a partir de perdas e ganhos intrínsecos ao processo de envelhecimento, no qual se adquire experiência ao passo que se perde a saúde. Influências socioculturais também foram destacadas nas representaçôes sociais compartilhadas pelas professoras que - em suas evocaçóes - apresentavam elementos relativos a categorias etárias como: terceira idade e velhice. Os autores discutem que a associação de tais elementos reflete as transformações na vida coletiva e social, o que denota uma possível futura modificação nos elementos representacionais do objeto envelhecimento, tal como proposto pela perspectiva do envelhecimento positivo.

Com objetivo de caracterizar as representaçóes sociais do envelhecimento apresentadas por estudantes italianos, Wachelke e Contarello (2011) utilizaram da técnica da evocação livre para investigar sete objetos sociais ligados ao envelhecimento, propondo uma relação entre as distâncias desses objetos. A partir da análise de similitude e - posteriormente - prototípica, foi identificado, para o envelhecimento, a aproximação de três objetos: morte, saúde e família. Os resultados indicam que o envelhecimento é representado a partir de elementos como morte, família, avós, bem como as pessoas idosas em geral. Desse modo, foram encontrados elementos positivos e negativos relativos ao envelhecimento, sendo que os elementos negativos parecem vinculados ao declínio físico tendo como consequência a morte, elementos representacionais que parecem similares à perspectiva do envelhecimento que - de acordo com Neri (2006) - foi enfatizada e popularizada durante o século XX.

Ao investigar as representações sociais e envelhecimento em publicaçóes científicas no campo das Ciências da Saúde, Oliveira et al. (2012) destacam que - no período de 2000 a 2010 - as pesquisas acerca das representações sociais do envelhecimento apresentam em seus resultados elementos relativos ao idoso, associado à qualidade de vida, autonomia e respeito no espaço familiar. Os autores destacam também a presença de elementos representacionais relativos a grupos de convivência, na condição de espaços sociais que permitem a transformação da imagem da velhice monótona, sofrida e estereotipada em uma velhice ativa. Nesse sentido, parece que os grupos de convivência promovem o envelhecimento positivo descrito por Gergen e Gergen (2000), pois gradativamente favorecem a modificação da imagem atribuída ao idoso.

Desse modo, os elementos da representação social do envelhecimento podem sofrer alterações de acordo com o contexto, havendo semelhanças e diferenças 
apresentadas em cada situação específica de interação social. Considerando as mudanças decorrentes do advento da internet, há modificações nos elementos que estruturam as representações sociais da velhice? Quais as representações sociais do envelhecimento emergentes na era digital?

\section{A "MELHOR IDADE" E O ENVELHECIMENTO NA ERA DIGITAL}

Ao discorrer acerca da comunicação de massa, Kientz (1973, p.18) reafirma seu caráter unilateral durante o período Industrial, onde uma minoria produzia mensagens para que a grande massa as recebesse em silêncio. No entanto, é possível considerar que as novas tecnologias e redes computacionais impuseram novos muros para a população mundial, em que os grupos sociais não são mais separados ou agrupados em decorrência de fronteiras geográficas, mas, agrupados por esferas cognitivas e epistemológicas por meio de muros fluidos. Um mesmo indivíduo pertence a vários grupos sociais simultaneamente; suas relações de pertencimento, suas atitudes, são adaptadas a cada um dos papéis desempenhados nos diversos grupos sociais (Tuzzo, 2004).

$\mathrm{Na}$ Era digital, o modelo de comunicação da internet apresenta as relações de pertencimento a partir do pressuposto da interatividade, em que o receptor pode tornar-se emissor e vice e versa. Em alguns casos em que o receptor torna-se simultaneamente - comunicador, esse tem o poder de influenciar o comunicador no próprio instante da geração e transmissão de sua mensagem. Além disso, o receptor na internet pode selecionar os grupos com os quais compartilha ideias e com as quais quer se filiar, assim torna mais provável o compartilhamento de assuntos afins e a consequente multidirecionalidade entre emissor e receptor (Castells, 2003).

Não é possível estabelecer comunicação sem a partilha de determinadas representações, e uma representação é compartilhada e entra na herança social do indivíduo quando ela se torna um objeto de interesse e de comunicação (Moscovici, 2003). As representações sociais têm a comunicação de massa como condição de possibilidade e determinação. Por meio da comunicação, é possível suscitar debates na esfera pública, trazendo uma determinada temática para o interior das conversas sociais (Jodelet, 2001). Desse modo, o conhecimento social é criado e recriado, tendo como condutores os veículos de comunicação social (Camargo, 2003).

Quando os meios de comunicação e troca de informações sofrem aprimoramentos, com a popularização da internet, o fluxo de comunicação aumenta consideravelmente. $\mathrm{O}$ poder passa dos mais idosos, com extensa 
memória e experiência de vida, para a rede de comunicação rápida. $\mathrm{O}$ advento da internet como algo "novo", em contraposição à figura do idoso como algo "velho" levanta questionamento acerca de possíveis novos elementos da representação social do envelhecimento.

Novos meios de comunicação estabelecem ao usuário maior necessidade em serem ativo e produtivo em termos de cocriação de conteúdo. Isso pode indicar uma nova noção de exclusão digital, a partir da divisão entre aqueles que apenas consomem e aqueles que produzem ou cocriam conteúdos para comunicação virtual (Karahasanovi et al., 2009). Parte da população idosa possui um sentimento de exclusão social pela falta de conhecimentos tecnológicos, e alguns se tornam apenas consumidores dos conteúdos online; no entanto, tendo em vista as vantagens do uso da internet para a ampliação das redes sociais, os idosos vêm procurando muito mais o processo de informatização e de compartilhamento de conteúdos online (Kachar, 2010). O número de idosos com acesso à internet tem aumentado nos últimos anos: segundo dados do IBGE de 2005 a 2011, mais 5,6 milhôes de pessoas com 50 anos ou mais passaram a acessar a internet no Brasil.

Entre as redes sociais para compartilhamento e criação de conteúdo, o Facebook, o YouTube, WhatsApp e o Instagram estão entre os sete portais com maior número de usuários. O Facebook mais de 2 bilhôes de usuários, enquanto o YouTube, surge com cerca de 1,5 bilhão (Statista, 2018) A partir das redes sociais, os usuários podem tornar disponível para acesso público, suas próprias imagens, músicas e vídeos; além disso, os usuários podem identificar e procurar outros usuários no site, facilitando o estabelecimento e/ou manutenção de um grupo de amigos e gerando novas formas de capital social.

O capital social, conforme Bourdieu (1983) é a "soma de recursos" que está disponibilizada pela rede, relacionada às conexóes que os atores possuem, apresentando certo valor ou benefício para os indivíduos que participam nesta rede. Com o objetivo de explorar as diferenças de potencial no capital social, entre os idosos em comparação com o dos adolescentes, Pfeil, Arjan e Zaphiris (2009) realizaram uma pesquisa por meio de 6000 perfis de usuários da rede social MySpace. Os autores destacam que os adolescentes utilizam as redes sociais principalmente para se conectar e interagir com seus pares offline, que apresentam faixa etária similar. Os idosos utilizam as redes sociais principalmente para transferir ligações off-line para o relacionamento virtual; em seguida, manter e expandir o seu capital social neste cenário virtual. Nesse sentido, parece que as redes sociais são utilizadas - principalmente - para manter e nutrir o capital social que decorre das relações mantidas fora do espaço virtual. 
O computador e as novas tecnologias de informação podem descaracterizar a velhice como um período de limitações e perdas ao possibilitar que o idoso que possui acesso à internet, sinta-se inserido na sociedade, por meio da troca de informações e atualizações que o ambiente virtual permite (Kachar, 2010). Em pesquisa - desenvolvida por Santana, Côrte, Lodovici, \& Alves (2013) - os idosos associam internet à eficiência e praticidade; na condição de veículo para buscar amigos ou encontrar novos, evitando a solidão ao ampliar a rede de relações para além da familiar. Nesse sentido, os idosos buscam acompanhar a evolução tecnológica e os progressos na comunicação, para diminuir o isolamento, sentirse parte integrante deste novo mundo, sendo que esse contexto de interações pode favorecer a promoção do envelhecimento ativo e contribuir para o envelhecimento bem sucedido, como um mecanismo compensatório diante das perdas.

Para investigar as necessidades de idosos relacionados ao consumo, a partilha e a cocriação de conteúdos em novas mídias Karahasanović et al. (2009) realizaram três estudos. $\mathrm{O}$ primeiro estudo, realizado na Noruega, o segundo e o terceiro estudo, realizados na Bélgica. Os dados encontrados por Karahasanović et al. (2009) indicam que entre os idosos os interesses em serviços e conteúdos disponibilizados na Internet incluem - principalmente - o uso de e-mail, verificação de notícias, informações sobre saúde, navegação por diversão e atualizações de tempo. O idoso tende a desconsiderar o uso de redes sociais e comunidades virtuais quando identifica que os conteúdos compartilhados em ambiente virtual não podem satisfazer as suas necessidades e desejos em relação ao afeto, a integração pessoal, filiação e liberação de tensão. Outros fatores que diminuem o interesse na utilização de redes sociais incluem o medo de que os sistemas são muito difíceis de aprender e a falta de influência social: quando os usuários não se sentem motivados por seus familiares ou amigos para a utilização das ferramentas da internet (Karahasanović et al., 2009).

A memória coletiva é relevante no contexto do compartilhamento de informações no ambiente virtual. Os internautas idosos gostam de olhar para o passado e relembrar a vida a partir de imagens e vídeos, utilizando recursos da memória relativa a fatos históricos para se expressar politicamente. Após suas publicações em redes sociais, ao receberem e-mails ou comentários em suas páginas pessoais, os internautas idosos sentem-se motivados para continuar o compartilhamento de informaçóes online. Assim, os idosos estão gradativamente reconhecendo os aspectos afetivos, integrativos e criativos que envolvem o compartilhamento de informações na internet e com auxílio operacional dos familiares tornam-se mais propensos ao uso das redes sociais e comunidades virtuais, principalmente para a expressão de opiniōes e retomada de fatos passados (Karahasanović et al., 2009). 
O envelhecimento tem ganhado espaço nas discussões cotidianas a partir de comunidades na internet específicas à temática. Termos como "melhor idade" ou "terceira idade" são - cada vez mais - adotados em páginas na internet que apresentam informaçôes relativas à saúde e ao lazer. O termo "terceira idade" foi apresentado nos anos 60 para designar a faixa etária intermediária entre a vida adulta e a velhice (Neri \& Freire, 2000, p. 13). Conforme Debert (1997), o uso corrente do termo terceira idade entre os pesquisadores não é explicado pela referência a uma idade cronológica: é utilizada como forma de tratamento das pessoas idosas, por não apresentar uma conotação depreciativa.

A internet constitui um importante fator de estruturação das redes de suporte emocional do idoso, podendo contribuir para a integração social dos indivíduos mais velhos. Ao acessar redes sociais e páginas voltadas à discussão do envelhecimento, é possível encontrar atrelado ao processo, definiçóes relativas à terceira idade, associadas à concepção de "melhor idade" (Silva, 2013). A partir de uma pesquisa simples em ferramentas de busca online, é possível localizar cerca de 396.000 páginas que oferecem produtos ou fazem divulgação de informações relacionadas à "melhor idade". Há uma tendência nessas publicações a desconsiderar as perdas inerentes ao processo de envelhecimento, mascarando características negativas e enfatizando maiores possibilidades de lazer aos idosos (Bringmann et al., 2012).

A partir das atividades sociais e com o desenvolvimento de grupos voltados aos idosos e a construção social da "terceira idade", houve a propagação da ideia da "melhor idade" em oposição à velhice, o que parece corresponder a ideia de desconstrução das imagens negativas do envelhecimento proposta por Gergen e Gergen (2000). Em relação à velhice como objeto social, o estudo de Magnabosco-Martins et al. (2009) traz importante contribuição. Em seus principais resultados, destacam que os idosos compartilham a ideologia da "boa idade", difundida nos grupos da "terceira idade", considerando que ser velho, ou estar na velhice depende do comportamento e pensamentos de cada pessoa. Ao passo que os não idosos apresentam uma ideia de velhice vinculada a perdas, transformações orgânicas e psicológicas, objetificada na figura do idoso e associada à sabedoria e experiência.

A imagem acerca da "terceira idade" propagada por intermédio dos meios de comunicação apresenta os idosos como indivíduos autônomos, independentes dos familiares, ativos, capazes de encontrar uma série de atividades novas nessa etapa da vida; contudo, desconsideram as dificuldades, mesmo diante dos mecanismos para lidar com os problemas da velhice avançada. Assim, a imagem do envelhecimento - associada à da "melhor idade" - pode não oferecer instrumentos para o enfrentamento dos problemas relativos às perdas cognitivas, 
físicas e emocionais. Diante dessa nova categoria social, o idoso que apresenta problemas oriundos do processo de envelhecimento pode vir a ser marginalizado, não encontrando apoio social diante das dificuldades na velhice (Debert, 1997).

A concepção de "melhor idade", proposta socialmente, principalmente nas páginas da internet, não destaca as experiências dos idosos, relativas às dificuldades sociais, orgânicas ou emocionais durante o processo de envelhecimento. Assim, a propagação da terceira idade como "melhor idade", com a supervalorização dos ganhos advindos do envelhecimento, pode responsabilizar os indivíduos pela perda de habilidades e controles físicos e emocionais que o processo de envelhecimento desencadeia (Debert, 1997). Magnabosco-Martins et al., (2009) - ao estudarem as Representaçôes sociais do idoso e da velhice - identificam que o idoso considerado feliz é aquele que permanece ativo e atualizado diante de novas informações, adaptando-se ao ritmo e desejos de seus familiares. Desse modo, é possível verificar que as representações sociais do envelhecimento associadas - exclusivamente - a ganhos, que traçam um perfil ideal de idoso, relativo à atividade, atualização e felicidade, podem influenciar na adoção de práticas sociais pouco adaptativas diante das perdas decorrentes da velhice.

\section{CONSIDERAÇÕES FINAIS}

As definições acerca do envelhecimento passam por constantes adaptações e modificações ao longo dos períodos históricos. Objeto de definições variadas, a velhice pode suscitar representações sociais distintas, dependendo da temática a que seja associada: envelhecimento, terceira idade, velhice e pessoas idosas. Embora o envelhecimento seja considerado um processo - e não uma fase do ciclo vital - grande parte dos estudos acerca do envelhecimento apresenta a velhice como objeto equivalente para o pensamento social, em que a objetificação da representação do envelhecimento ocorre por meio da figura do idoso (Magnabosco-Martins et al., 2009).

O processo de envelhecimento e a fase da velhice são objetos equivalentes no âmbito do pensamento social. É considerado velho aquele que assim se sente, que não participa da realidade social, que se associa à velhice. No entanto, é considerado idoso aquele o que tem idade avançada, mas que não sente os sinais da velhice, mantendo-se ativo e em pleno exercício das funções mentais (Magnabosco-Martins et al., 2009).

As características socioculturais e psicossociais são relevantes para o modelo de envelhecimento bem sucedido, em que se compreende que o processo de desenvolvimento ocorre durante toda vida, envolve perdas e ganhos ocasionados pelo envelhecimento e influenciados pelo contexto em que se encontra o 
indivíduo. Nesse sentido, é possível afirmar que diferentes representações podem ser elaboradas acerca de um mesmo objeto, associadas às atividades do grupo e às suas características culturais. Em relação às representaçôes sociais de um objeto como o envelhecimento - por exemplo - parece fundamental identificar o grupo que as veicula, situar seu conteúdo simbólico no espaço e no tempo e identificar seu contexto intergrupal característico.

O fenômeno do envelhecimento populacional, as facilidades tecnológicas e o aumento da oferta de bens e produtos voltados aos idosos, podem trazer novos elementos para o estudo das representações sociais do envelhecimento. Tendo em vista que - gradualmente - tem aumentado o número de idosos com acesso à internet, cresce proporcionalmente o número de páginas e comunidades online que discutem o envelhecimento e seus aspectos. No ambiente virtual, termos como "melhor idade" ou "terceira idade", são adotados em páginas da internet que apresentam informaçóes referentes à saúde e lazer para os idosos. $\mathrm{Na}$ perspectiva do envelhecimento positivo, o uso corrente do termo "terceira idade" ou "melhor idade" parece tentar desconstruir as imagens negativas associadas ao envelhecimento (Debert, 1997). Nas postagens online, aspectos vinculados às perdas decorrentes do envelhecimento são minimizados, a identidade relativa à "terceira idade" está associada às características positivas da velhice, tratando esse grupo etário como "melhor idade".

A imagem do envelhecimento, associada à da "melhor idade", é favorável à resignificação da velhice, pois destaca possibilidades de lazer, atividades, visando à melhoria da qualidade de vida. Por apresentar maior destaque aos ganhos advindos do envelhecimento, essa perspectiva pode não oferecer subsídios diante das perdas cognitivas, físicas e emocionais. A ênfase nos ganhos - com a chegada da velhice com destaque - para a "melhor idade" favorece a desconstrução da velhice associada a doenças, morte e inatividade, mas parece desconsiderar outras possibilidades de envelhecer (Debert, 1997). É necessário enfatizar a pluralidade de experiências de envelhecimento, em que o envelhecimento bem sucedido reflete o equilíbrio entre ganhos e perdas nesse processo.

Os debates online por meio de comunidades e redes sociais influenciam nas elaborações de representações sociais acerca do envelhecimento e - possivelmente - orientam as práticas sociais. Nesse sentido, a internet oferece um promissor campo para a pesquisa em representações sociais, em que os objetos se tornam cada vez mais fluidos e transitórios, dentre os quais foram aqui destacados elementos representacionais acerca do envelhecimento, velhice e terceira idade. 


\section{REFERÊNCIAS}

Abric, J. C. (1998). A abordagem estrutural das representações sociais. Estudos interdisciplinares de representação social, 2, 27-38.

Araújo, L. F., Coutinho, M. P. L., \& Saldanha, A. A. W. (2005). Análise comparativa das representações sociais da velhice entre idosos de instituições geriátricas e grupos de convivência. Psico, 36(2), 197-204. Recuperado a partir de http://revistaseletronicas.pucrs.br/ojs/index.php/revistapsico/article/ viewFile/1390/1090

Areosa, S. V. C. (2006). O que pensam as mulheres e os homens idosos sobre o seu envelhecimento? Textos \& Contextos, Porto Alegre, 3(1).

Baltes, P. B. \& Baltes, M. M. (1990). Psychological perspectives onsuccessful aging: the model of selective optimization withcompensation. In P. B. Baltes \& M. M. Baltes. Sucessful aging perspectives from the behavioral sciences. (pp. 1-34). Cambridge: Cambridge University Press.

Biasus, F., Demantova, A., \& Camargo, B. V. (2011). Representações sociais do envelhecimento e da sexualidade para pessoas com mais de 50 anos. Temas em Psicologia, 19(1), 319-336.

Bourdieu, P. (1983). The forms of capital. R. Nice. (pp. 248-257). [S.1.]: Marxists. Recuperado a partir de http://www.pontomidia.com.br/raquel/resources/03. html

Bringmann, G., Jung, M. M., Welter, E., Prates, F. L., Henz, L., \& Cruz, L. R. (2012). A população acadêmica da terceira idade na Universidade de Santa Cruz do Sul-UNISC. Revista Brasileira de Ciências do Envelhecimento Humano, $8(1), 148-157$.

Camargo, B. V. (2003). A televisão como vetor de difusão de informações sobre a aids. In M. P. L. Coutinho, A. S. Lima, F. B. Oliveira \& M. L. Fortunato (Eds.), Representaçôes sociais: Abordagem interdisciplinar (pp. 130-152). João Pessoa, PB: Universitária.

Castells, M. (2003). A Galáxia Internet: reflexōes sobre a Internet, negócios e a sociedade. Rio de Janeiro: Zahar.

Debert, G. G. (1997). A invenção da terceira idade ea rearticulação de formas de consumo e demandas políticas. Revista Brasileira de Ciências Sociais, 12(34), $39-56$. 
Fernandes deAraújo, L., Coutinho, M. da P., \& Saldanha, A. A. W. (2005). Análise comparativa das representações sociais da velhice entre idosos de instituições geriátricas e grupos de convivência. Psico, 36(2), 197-204. Recuperado a partir de http://revistaseletronicas.pucrs.br/ojs/index.php/revistapsico/article/ viewFile/1390/1090

Fernández, A.F. (2002). II Asamblea Mundial sobre el Envejecimiento. Revista Esp. Geriatr. Gerontol. 37(S2), 1-2

Fundo de População das Nações Unidas (2011). Relatório sobre a situação da população mundial 2011. Recuperado a partir de http://www.unfpa.org.br/ Arquivos/caderno_populacao6.pdf

Gergen, K. J., \& Gergen, M. M. (2000). The new aging: self construction and social values. (pp.281-306). New York: Springer. Recuperado a partir de http://www.swarthmore.edu/Documents/faculty/gergen/The_New_Aging. pdf

Instituto Brasileiro de Geografia e Estatística (2012). Sintese de indicadores sociais: uma análise das condiçôes de vida. Rio de Janeiro: IBGE. Recuperado a partir de ftp://ftp.ibge.gov.br/Indicadores_Sociais/Sintese_de_Indicadores_ Sociais_2012/SIS_2012.pdf.

Jodelet, D. (2009). Contributo das representações sociais para o domínio da saúde e da velhice. In Lopes, M., Mendes, F., Moreira, A. (Coords.). Saúde, educação e representaçôes sociais: exercícios de diálogo e convergência. (pp.71-88). Coimbra: Fomassau.

Jodelet, D. (2001) Representações sociais: um domínio em expansão. In: D. Jodelet (Org.). As representaçôes sociais. (pp. 17-41). Rio de Janeiro: EDUERJ.

Kachar, V. (2010). Envelhecimento e perspectivas de inclusão digital. Kairós. Revista da Faculdade de Ciências Humanas e Saúde. ,13(2).

Karahasanovi , A., Brandtzæg, P. B., Heim, J., Lüders, M., Vermeir, L., Pierson, J., \& Jans, G. (2009). Co-creation and user-generated content-elderly people's user requirements. Computers in Human Behavior, 25(3), 655-678.

Kientz, A. (1973). Comunicação de massa: análise de conteúdo. [S.l.]: Eldorado.

Magnabosco-Martins, C. R., Camargo B.V., \& Biasus, F. (2009, setembro/ dezembro). Representações sociais do idoso e da velhice de diferentes faixas etárias. UniversitasPsychologica, 831-847. 
Moliner, P., \& Vidal, J. (2003). Stéréotype de la catégorie et noyau de la représentation sociale. Revue internationale de psychologie sociale, 16(1), 157176.

Moscovici, S. (1985). Ecole des Hautes Etudes en Sciences Sociales. C. Schulse (Trad.). Paris: EHESS.

Moscovici, S. (2003). Representaçôes sociais: investigaçôes em psicologia social. Rio de Janeiro: Vozes.

Nagel, M. M., Contarello, A., \& Wachelke, J. (2011). Representações sociais e desafios além de fronteiras: estudando o envelhecimento em tempos de mudança. Temas em Psicologia, 19(1), 59-73.

Neri, A. L. \& Freire, S. A. (Orgs.) (2000). E por falar em boa velhice. Campinas: Papirus.

Neri, A. L. (2006). O legado de Paul B. Baltes à Psicologia do Desenvolvimento e Envelhecimento. Temas em Psicologia, 14(1), 17-34.

Neri, A. L. (2008). Desenvolvimento e envelhecimento: perspectivas biológicas, psicológicas e sociológicas. (4a. ed.). Campinas, SP: Papiru.

Neri, A. L. (2013). Conceitos e teorias sobre o envelhecimento. In: MalloyDiniz, L et al. (Eds.), Neuropsicologia do envelhecimento: uma abordagem multidimensional. (pp. 17-42). Porto Alegre: Artmed.

Oliveira, A. M. D. M., Lopes, M. E. L., Evangelista, C. B., Oliveira, A. E. C. D., Gouveia, E. M. L., \& Duarte, M. C. S. (2012). Representaçôes sociais e envelhecimento: uma revisão integrativa de literatura: Social representations and aging: an integrative review of the literature. Revista brasileira de ciências da saúde, 16(03), 427-434.

Pecora, A. R., dos Anjos, P. M., \& Paredes, E. C. (2010). O envelhecimento como processo social. Aging as a social process. Revista de Educação Pública, 19(39), 55-73. Recuperado a partir de http://cacphp.unioeste.br/extensao/unati/arqs/ UNATI_11.pdf

Pfeil, U., Arjan, R., \& Zaphiris, P. (2009). Age differences in online social networking-A study of user profiles and the social capital divide among teenagers and older users in MySpace. Computers in Human Behavior, 25(3), 643-654. 
Santana, M. A., Côrte, B., Lodovici, F. M. M., \& Alves, V. P. (2013). Aliando Tecnologia da Aprendizagem à Qualidade de Vida dos Idosos. Revista de Estudios para el Desarrollo Social de la Comunicación, (7), 269-280.

Silva, P. M. T. D. (2013). As redes de suporte emocional de indivíduos de 50 e mais anos na Europa: a interação mediada por computador. (Dissertação de Mestrado). Universidade do Minho, Programa de Pós-Graduação em Sociologia. Braga.

Statista. (2018). Internet usage worldwide. Retrieved. Recuperado em 12 junho, 2013 de < https://www.statista.com/statistics/272014/global-social-networksranked-by-number-of-users/>.

Teixeira, M. C. T. V., Schulze, C. M. N., \& Camargo, B. V. (2002). Representações sociais sobre a saúde na velhice: um diagnóstico psicossocial na rede básica de saúde. Estudos de Psicologia, 7(2), 351-359.

Teixeira, M. C. T. V., Franchin A. B. B., Durso F. A., Donati L. B., Facin M. M., \& Pedreschi P. (2007). Envelhecimento e rejuvenescimento: um estudo de representação social. Revista Brasileira de Geriatria e Gerontologia, 10(1) 4971. Recuperado a partir de http://revista.unati.uerj.br/scielo.php?script=sci_ arttext\&pid=S1809-98232007000100005\&lng=pt

Tuzzo, S. A.(2004). Deslumbramento coletivo:opiniāopública, midia e universidade. São Paulo: Annablume.

Veloz, M. C. T., Nascimento-Schulze, C. M., \& Camargo, B. V. (1999). Representações sociais do envelhecimento. Psicologia: Reflexão e Crítica, 12(2), 479-501.

Wachelke, J. F. R., Camargo, B.V., Hazan, J.V., Soares, D.R., Oliveira, L. T. P., \& Reynaud, P. D. (2008). Princípios organizadores da representação social do envelhecimento: dados coletados via internet. Estudos de Psicologia (Natal), 13(2), 107-116. Recuperado a partir de http://www.scielo.br/pdf/epsic/ v13n2/02.pdf

Wachelke, J., \& Contarello, A. (2011). Italian students' social representation on aging: an exploratory study of a representational system. Psicologia: Reflexão e Critica, 24(3), 551-560. 